
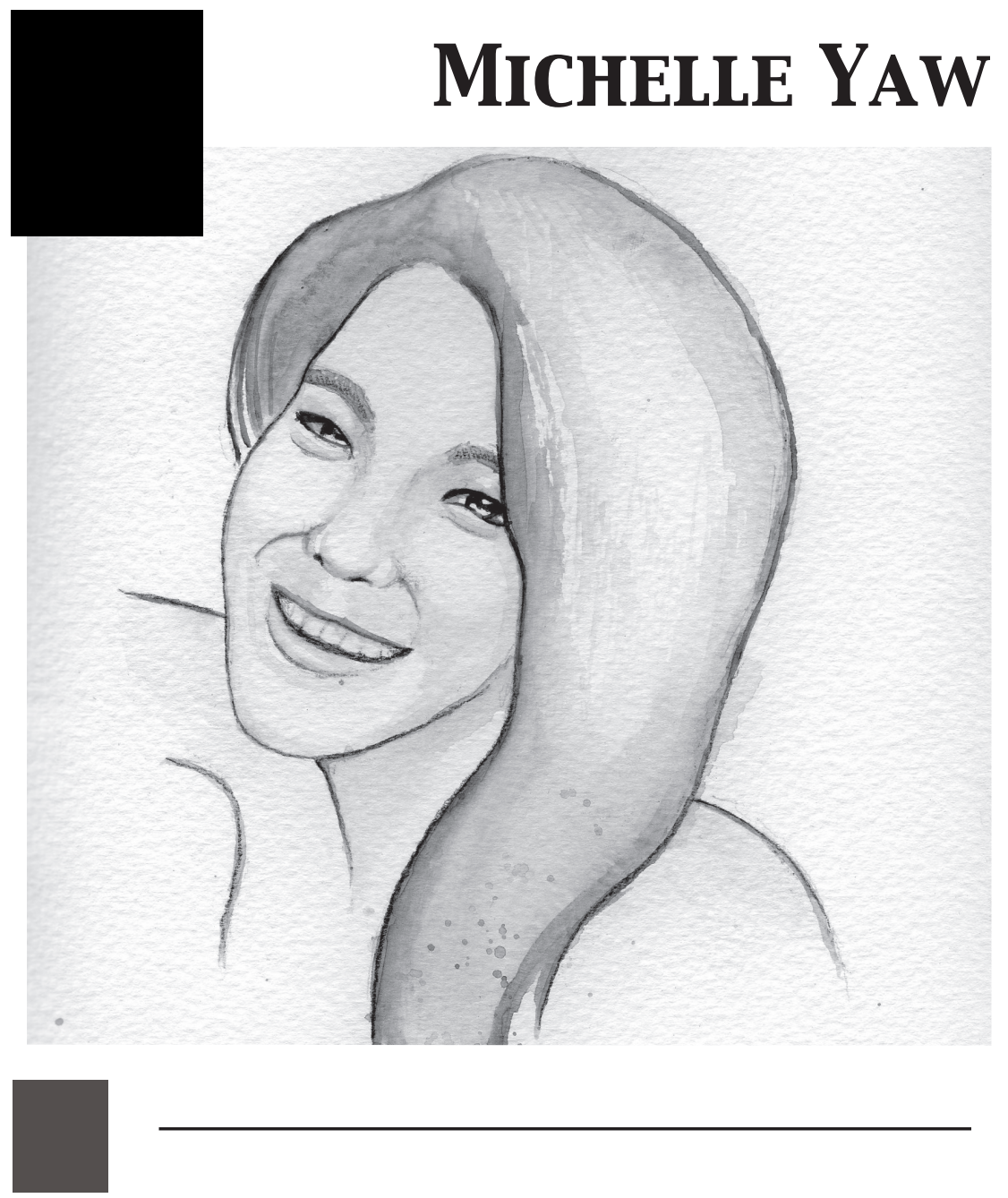

As a Malaysian growing up in Singapore, Asian culture (and especially Southeast Asian politics) has been an integral part of Michelle Yaw's life. Like many contributing to this journal, she believes that the visual arts can influence and shape society. Studying Art History at Georgetown University has allowed her to explore the intersections between art, international politics theory, and social realities. "Old Tensions, New Meanings, More Healings" reveals her interest in the various endeavors of the art world as well as in Cambodian art, sparked by her experience in a community development project in Phnom Penh. 


\section{OLD TENSIONS, NEW MEA NINGS, MORE HEALING \\ AN ANALYSIS OF THE SEASON OF CAMBODIA, CAMBODIAN RATTAN: THE SCULPTURES OF SOPHEAP PICH}

\section{Introduction}

Throughout April and May of 2013, ten elegantly latticed rattan sculptures were hung amidst the gallery spaces of the Metropolitan Museum of Art's South and Southeast Asian galleries. Cambodian artist Sopheap Pich (b.1971), the centerpiece for the museum's contribution to the Season of Cambodia: A Living Arts Festival, created these sculptures. The exhibition was promoted and perceived as the highlight of the national cultural festival organized by Cambodian Living Arts (CLA) and a variety of institutions in New York City. Along with this, the Season of Cambodia and the Met presented Pich as the pioneering symbol of Cambodian visual artistic revival, in contrast to most approaches to national cultural festivals which either focus on the propagandistic messages of the country's organizers or criticize the festival's exhibitions as "self-Orientalizing." The literature surrounding Pich applauds his artistic development as an internationally recognized Cambodian artist. ${ }^{2}$ However, the juxtaposing approach of the Met's special exhibition, as well as the "young" flare of the Season of Cambodia, calls for a more subtle analysis of Cambodian Rattan as part of the urgent debates regarding post-conflict resolution.

The role of Sopheap Pich's work at the Met exhibition is less of a result of his "Cambodian artistic genius" than a constructed product of the intersecting agendas of the different organizers. On one hand, Pich's work fits with the "new cultural renaissance" image promoted by the CLA, who hope to extinguish the general perception of Cambodia as the once-great Angkor Kingdom that turned into a horrific economic and cultural desert after the Khmer Rouge purging. On the other hand, by showcasing a contemporary Cambodian artist within the permanent 
South and Southeast Asian galleries, the Met uses Pich's works to emphasize the museum's commitment to contemporary art in developing nations. Importantly, the motivations of these partners are framed and complicated by tensions involved in using art to assess the success of post-conflict resolution. While the CLA believes that international support for Pich's art will help Cambodians overcome trauma and contribute to civilian-driven peace building, the Met designates craft in Pich's work as an aesthetic and psychological gesture for "authentic" Cambodian, and even Asian, contemporary high art. The tensions played out in Cambodian Rattan bring to light an attempt to challenge Western ideas of Cambodian art and culture through unconventional festival exhibition strategies and an emphasis on craft in Pich's art. Yet, the solo retrospective might also reinforce certain Western assumptions about Cambodia's post-conflict resolution process and international relations. In light of emerging art historical, museum, and post-conflict discourse, this paper argues that Cambodian Rattan demonstrates the complex relationship between national culture festivals, economic development, and political institutions.

\section{Season of Cambodia and Post-Conflict Reconstruction}

With a mission to "serve as a symbol of [the] country's resilience as a post-conflict nation and reflect[...] Cambodia's thriving cultural development," 3 the Season of Cambodia showcased a variety of Cambodian musicians, dancers, and visual artists through highly publicized exhibitions, performances, lectures, and workshop activities at partner institutions in New York. The cultural festival was considered a successful form of "cultural diplomacy," as it provided a platform for post-conflict Cambodia. Cambodia's current third-world status and identity remains influenced by the impact of the Democratic Kampuchea (DK) regime (1975-1979) ${ }^{4}$ and its social reengineering drives to create a classless, agrarian society. ${ }^{5}$ Artisans were attacked and any form of artistic production associated with elite intellectual bourgeois was banned. Today, the corruptions of the government as well as the country's poverty issues 


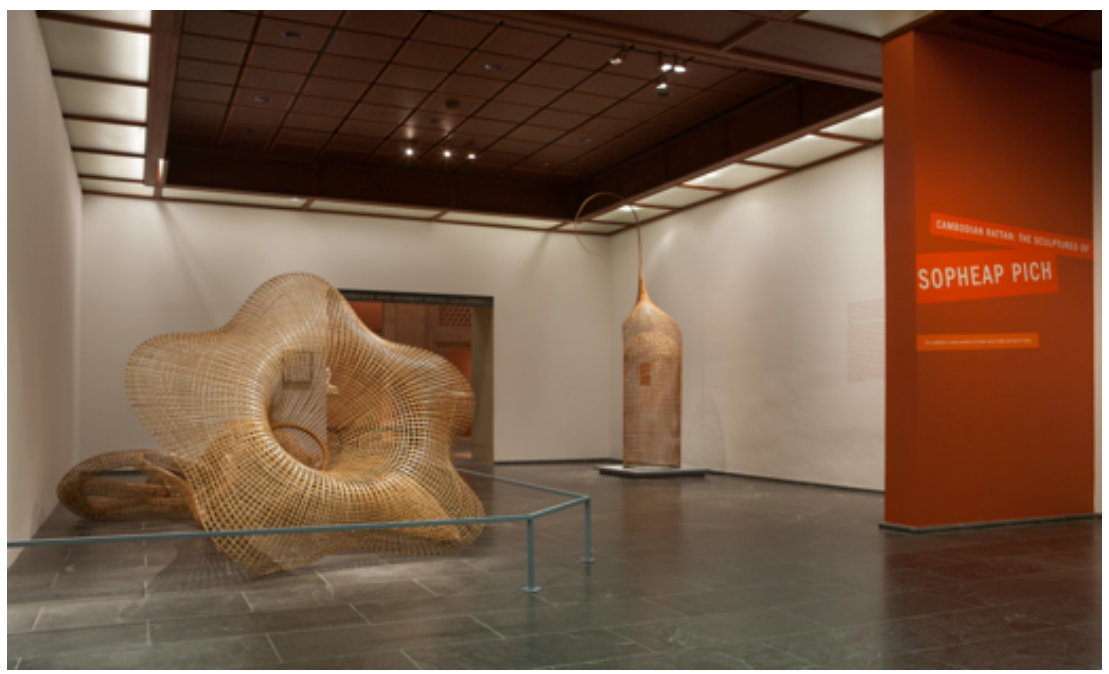

Figure 1. From Left: Sopheap Pich, Morning Glory (2011). Rattan, bamboo, wire, plywood, steel bolts. $210 \times 103 \times 74$ in. $(533.4$ x $261.6 \times 188$ cm). Sopheap Pich, Stalk Version 2 (2009). Bamboo, rattan, wire. $144 \times 54 \times 26$ in. $(365.8 \times 137.2 \times 66 \mathrm{~cm})$. The Met. New York City. Image (C) The Metropolitan Museum of Art.

shape international post-conflict reconstruction efforts. Like many in Cambodia's significant NGO sector, the CLA is an organization founded by a returnee who supports "civil social development" through the arts. ${ }^{6,7}$ The CLA aims to nurture, empower, and promote the efforts of Cambodia's younger generation to learn by reinterpreting the country's cultural traditions as a form of "capacity-building." 8,9 The Season of Cambodia encompassed CLA's renewed mission to raise awareness and financial support for Cambodia's young artists. Sopheap Pich, an Amherst and School of the Art Institute of Chicago graduate and ex-refugee, had recently gained some recognition in the international art world. Represented by the leading Tyler Rollins gallery, Pich has exhibited at international galleries, particularly in Australia, Southeast Asia, and biennials like the Asian Art Biennial (2011), Documenta 13, and Singapore Biennial. Pich's work was showcased in several Season of Cambodia events ${ }^{10}$, and his sculptures were exhibited at the Met. During a timely period that coincided with the Cambodian national day and the recent death of King Norodum Sihanouk (1922-2012), Cambodian Rattan drew audiences of the Cambodian citizen and diaspora community as well as New York residents and tourists to the retrospective, composed by the CLA and Met to call upon a renewed interest in Cambodia's post-conflict future. 


\section{Cultural Revival and Cambodian Contemporary Art}

As with all Season of Cambodia activities, but especially Cambodian Rattan, the CLA organizers portray a thriving cultural society that successfully overcomes trauma through expression and innovation in the arts. This constructed image was meant to supersede traditional assumptions about Cambodia's present identity: that of a romantic lost Angkor civilization to a contemporary Kampuchean holocaust. These two opposing points frame Western ideas (French colonialism and American liberal democracy) of the "other" Cambodia in its post-conflict state. Cambodian Rattan attempts to deconstruct and reform the view of Cambodia's fall from the zenith of the Angkor Empire $\left(10^{\text {th }}-15^{\text {th }}\right.$ centuries) when Khmers dominated Southeast Asia. The ancient temples and sculptures that were to form a large part of the Met's Southeast Asian collections were venerated by colonial tastes as artistic masterpieces. ${ }^{11}$ Such images associated with Cambodia's violent but thriving golden age are supplanted by stark images of Pol Pot's killing fields and Tuol Sleng signifying an intellectual and artistic vacuum since "Year Zero." Wary that a gaze of Cambodia as stagnated by trauma might in turn hamper the efforts of Cambodia to develop, the CLA sought to expand the scope of common Western ideas to include a progressive future. ${ }^{12}$ In this sense, Edward Said's post-colonial divide between the Self/Occident and the Other/Orient situates an asymmetrical perception of a post-Khmer Rouge desert alongside an "authentic" revived Cambodia throughout the Season of Cambodia. Importantly, while these contrasts create certain tensions, the CLA does not vehemently reject the effect of post-conflict trauma in Cambodia. Rather, it is the very process of dispelling the externally formed image that catalyzes CLA's post-conflict reconstructing efforts of helping Cambodians face and overcome trauma.

In order to counter Western perceptions of cultural stasis, the Season of Cambodia had a particular emphasis on youth, change, and newness. As indicated by the festival's temporal title, events signaled that a new generation of Cambodians were ushering in a season of hope, progress and artistic revival. While the preserved practices of "old" masters were celebrated, ${ }^{13}$ organizers looked passionately forward at contemporary cultural production, rather than back in time. This strategy 
stands in contrast to other national cultural festival exhibitions that Brian Wallis notices hold exhibitions of national artifact "treasures."14,15 Furthermore, the CLA and Met activated a self-critiquing approach to turn Cambodia's negative image into a positive one while avoiding "self-Orientalizing" the artist on display. ${ }^{16}$ By exhibiting contemporary works in Cambodian Rattan, both institutions displaced expectations about what constitutes national Cambodian art. The ancient sculptures of the Angkor kingdom are as relevant to Cambodians as new art made by artists who break away from the horror that plagued their society. Immediately, Pich's abstracted sculptures struck viewers as unexpectedly "contemporary" as they appear to align with Western notions of modern or contemporary art. Additionally, the exhibition material, wall labels, and lectures held in conjunction with Cambodian Rattan emphasized Pich's ability to traverse "Oriental" definitions of Asian art and art making. Therefore, instead of dramatizing conventional versions of Cambodia's national image, Season of Cambodia's Cambodian Rattan avoids amplifying the destruction of the Khmer Rouge or Cambodian artistic heritage and shifts the Western gaze towards a hopeful, youth-centered culture and art.

This progressive, positive tone attracts the foreign support so essential to CLA's efforts in Cambodia. A declaration of a "new cultural renaissance" and "revival" permeated the Season of Cambodia appealing to Cambodians and Americans to support young Cambodian artists financially and socially. Such rhetoric denotes two of the CLA's claims in post-conflict resolution efforts. First, it wanted to demonstrate the psychological and economic positives of engaging the arts in post-conflict peace building ${ }^{17}$. Along with the rising acceptance of art therapy in the field of psychology, ${ }^{18}$ Season of Cambodia sought to connect the healing from trauma to the revival in artistic production. In this vein, Cambodia's artists have broken away from the "pathologisation" of failed states, ${ }^{19}$ contributing significantly to the art world and, by extension, the international world. Secondly, the festival itself is meant to be a model for other post-conflict communities and nations. ${ }^{20}$ The international recognition of Pich is thus extrapolated to the future success of other young Cambodian visual artists who were featured in the Season of Cambodia in other partner institutions. For Cambodians and the di- 
aspora, the "revival" of Cambodian arts increases national and ethnic pride, encouraging financial contributions to the country. Even though all the organizations involved were separate from the government, the Season of Cambodia was a festival of and for the people as a nation. The artist and his work become synonymous with the cultural maturity of a resilient "imagined community." 11,22 For American viewers, there is a cultural and moral impetus to support Cambodia's new renaissance and help to lead it further into the $21^{\text {st }}$ century via professional expertise and monetary support. This transitional "season" is the overarching urgency for international support and the underlying possibility of "missing out" on the opportunity to catalyze and foster regeneration in a post-conflict society. ${ }^{23}$ CLA's ability to gain the attention of the Met, an international cultural authority, also legitimizes its claim of artistic revival.

As such, the partnership of the Season of Cambodia and the Met downplayed existing political tensions and the unfinished post-conflict resolution process. None of the institutions that worked with the Season of Cambodia were associated with the Cambodian government according to CLA co-founder John Burt. Hun Sen has been accused of immense corruption. Trials of ex-Khmer Rouge members give rise to domestic and international contention, dissatisfaction and disillusionment. ${ }^{24}$ Observing these "truth-telling justice" events, ${ }^{25,26}$ academics and policymakers debate and assess the effectiveness of international law and post-conflict reconstruction methods. The CLA, however, places itself and the Season of Cambodia in a different sphere of contention where art reveals the achievements of post-conflict resolution. Moving away from the potential for political controversy, the Met's selection of Pich's less activist works displayed little open criticism of the government. ${ }^{27}$ Though Pich himself avoids commenting on politics ${ }^{28}$ some of his other sculptures like Compound (2011) ${ }^{29}$ (See Figure 2) evoke more overt statements than the focus on universal themes of pollution and rural destruction in Cambodian Rattan (See Figure 3). Pich's work, curated to avoid overt politicization, proved a suitable balance to represent Cambodia's contested post-conflict image. Instead of playing to international attention pointing to friction, the CLA chose to stress hope for this social movement. The Met and CLA organizers proposed this multifaceted festival as an alternative model to the cynicism that plagues 


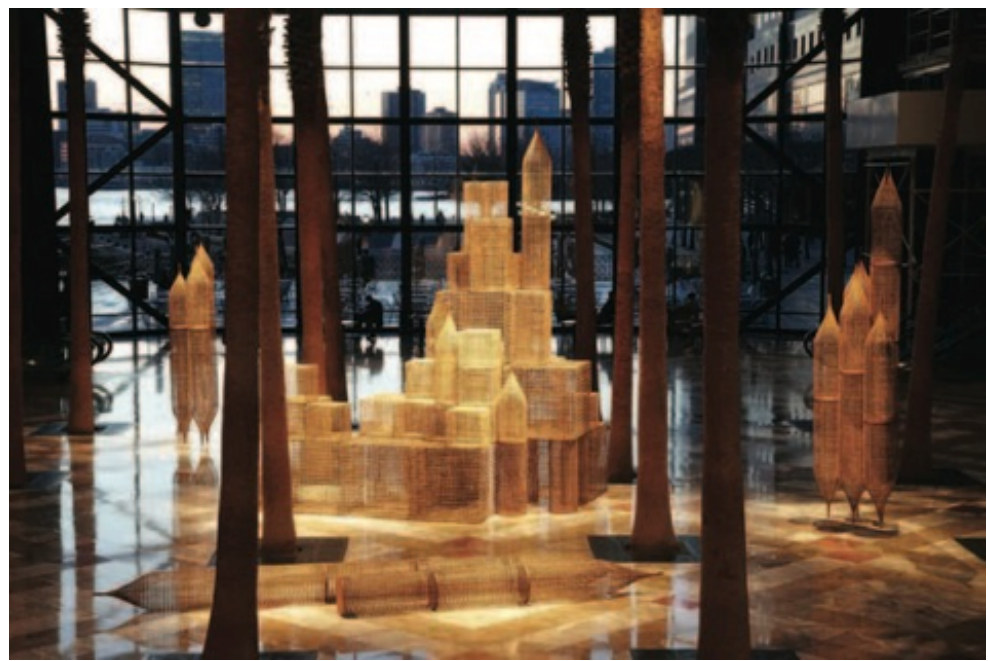

Figure 2. Sopheap Pich. Compound (2011). Bamboo, rattan, plywood, and metal wire. Brookfield Place Winter Garden, New York City. March 27-April 18, 2013. Courtesy of the artist and Tyler Rollins Fine Art. Photographer: Jesse Untracht-Oakner.

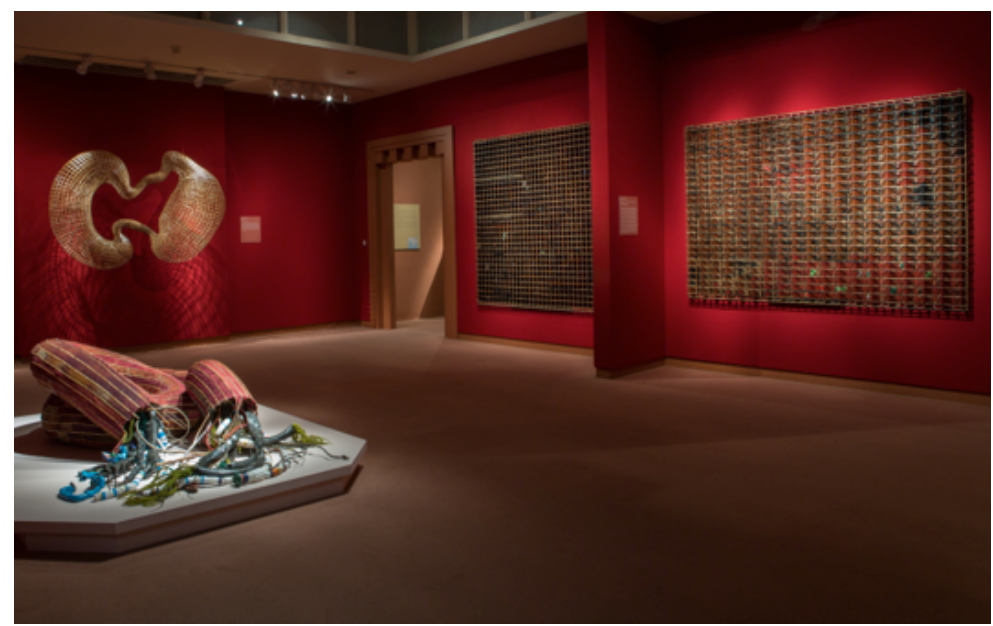

Figure 3. From Left: Sopheap Pich. Junk Nutrients (2009), Cycle 2, Version 3 (2008), Fields of Ratanakiri No. 2 (2012), Ratanakiri Valley Drip (2012). The Met. New York City. Image (C) The Metropolitan Museum of Art.

the image of Cambodia as a cultural desert.

\section{The Museum and Rethinking Cambodian Art History}

One of the main facets of Season of Cambodia was the Met's ex- 
hibition of Pich's sculptures that aligned with the festival's aims, the museum's institutional initiatives, and curatorial authority. Through the unconventional display approach in Cambodian Rattan and its choice of Pich, the Met portrays itself as an ethical, innovative, and discursive space, rather than just a historical site. In a sense, the Met, like the CLA, aims to expand the gaze of its audience through Cambodian Rattan.

Cambodian Rattan represents the Met's aims to become a serious competitor in the field of contemporary art. ${ }^{30}$ The exhibition is part of the increased number of contemporary art exhibitions, acquisitions and initiatives overseen by a new curator and a new department devoted to art of the $20^{\text {th }}$ and $21^{\text {st }}$ centuries. The Met's authority in the art world is built upon its encyclopedic collection of historic "masterpieces" over a span of time and space. Its recent institutional attentions expand the Met's conventional scope and appeals to different audiences. Indeed, for the Met to establish Pich as its first solo exhibit by a contemporary Southeast Asian artist speaks to both internal and external interests at play. Externally, the Met is building a relationship with Cambodia by becoming a leading partner in this cultural renaissance and thus as an educational resource to young generations or diaspora about Cambodia's art, her glorious past and future. As part of this diplomatic relationship, the Met announced the repatriation of two $10^{\text {th }}$ century Khmer statues or "Kneeling Attendants" that were smuggled out during the civil war of the 1970s. ${ }^{31}$ The repatriation also highlights the Met's professional willingness to meet growing concerns about museum collecting ethics. Along similar diplomatic lines, the museum's contribution to the festival through Cambodian Rattan materializes the Met's efforts to show support for contemporary art in Cambodia and other developing Asian countries.

While special contemporary art exhibitions at the Met are not new, Cambodian Rattan is particularly open about how it is exploring the relationship between old masterworks and "new" art of an emerging international artist. Works of major contemporary artists are installed on the Met's rooftop on a seasonal basis. "Representation/Abstraction in Korean Art" (Nov 2010-Mar 2011) is the only other exhibition that integrated contemporary art works of Asia with traditional works. An 
ability to experiment through the temporary exhibit thus proves helpful in merging the Met's interests with the Season of Cambodia's aims to dispel Cambodia's image as a scared, artistically drained country. Guy's innovative curatorial model followed Wagstaff's vision for the museum to be "in the vanguard of reinventing a new understanding of what art means." ${ }^{2}$ Sopheap Pich's work is therefore employed to expand the museum's stake in the art historical arena while showing how a museum can become a site of post-conflict reconciliation. As part of this model, the exhibition interweaves contemporary works to lend permanent pieces fresh interpretations and deeper understandings about the complexities of South and Southeast Asian art. The display choices of the curator also underscore his assertion that Pich is placing himself within post-colonial discourse. ${ }^{33}$ Pich's use of Western concepts of space, linearity and object combined with personal memories of Cambodia's resilience, religion and landscape keeps the artist's work in a transnational sphere of "Asian" art. The Met's permanent collection pieces are displayed in galleries that employ "masterpiece" practices of display in clean open spaces or in galleries that contextualize the works in "typical" architectural settings. Guy seems aware of the criticisms of such display formats that competes to define "Asia" ${ }^{34}$ and attempts to revitalize the permanent collection space with the freshness of Pich's sculptures. ${ }^{35}$

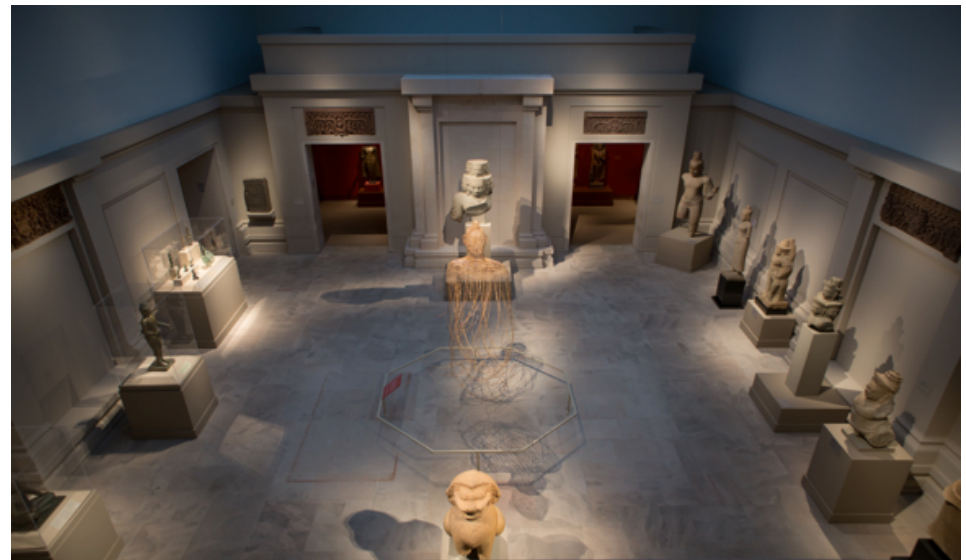

Figure 4. Sopheap Pich. Buddha 2 (2009). Rattan, wire, dye. H. 100 in. (254 cm); W. 29 in. $(73.7 \mathrm{~cm})$; D. 9 in. $(22.9 \mathrm{~cm})$. The Met. Exhibited in Gallery 249. New York City. Image (C) The Metropolitan Museum of Art.

In this vein, Pich's sculptures are strategically positioned to transform 
the decontextualized spaces and help to draw art historical relationships on aesthetic, religious and regional levels. By placing artworks that look "contemporary" next to Asian ancient objects, the show connects to the discourse stemming from the MOMA's "Primitivism" and Magiciens de la Terre. ${ }^{36}$ In one gallery, the juxtaposition of the ethereal hollowness of Pich's Buddha 2 against the solid resilience of Angkor stone sculptures suggests a haunting discontinuity between past and present in Cambodia (See Figure 4). Here, the Angkor sculptures, deemed by the colonial French ideas of Beaux-Arts as the epitome of ancient Khmer artistic mastery, signify traditional notions of Cambodian art and culture. Guy hangs the silhouette of a Buddha - cut short at the chest by strands of rattan with blood red tips - at the very center of the gallery space. This gesture dramatizes the gap between ancient traditional Khmer art and recent artistic destruction of the Khmer Rouge that stagnates the Western gaze of Cambodia. ${ }^{37}$ At the same time, the ghostlike piece echoes the forms of the surrounding sculptures, emphasizing the continued practice of Buddhism in Cambodia. As a result, the exhibition model encourages dialogue about colonial and post-Khmer Rouge ideas of Cambodian "essence." The show posits that the destruction of temples and cultural sites in Cambodia did not completely eliminate art making forever. In another gallery, the exhibition undercuts art historical narratives about the influence of Indian art on Southeast Asia, and thus, Cambodian styles by positioning Upstream within the vertical space of an Indian temple replica (See Figure 5). Pich's interpretation of fish traps is used to signify cross border interactions question misconceptions of Southeast Asian artistic originality. ${ }^{38}$ Such subtle, yet acute, relational display methods heighten certain art historical debates, encourage multiple readings and transform the Met's gallery spaces into sites where Cambodian contemporary art can help form a better understanding of South and Southeast Asian art. ${ }^{39}$

\section{Sopheap Pich: Craft as Authentic Cambodian High Art}

Furthering CLA's belief in the power of art in overcoming trauma, Cambodian Rattan places a national and artistic value on the elements of craft in Sopheap Pich's high art. In fact, the show's title ties national identity to the material of rattan, revealing that the Met distinguishes Pich's approach as not only high-end but also essential to understand- 
ing authenticity in Cambodian post-conflict reconstruction. Both organizations hope to assist a developing nation's post-conflict communities in overcoming trauma through art. Guy stresses the role of "memory and place"-psychological aspects of trauma — consistent in the art's content and medium. ${ }^{40}$ Distinguished from other visual artists featured during the festival, including the internationally recognized Leong Sekong, Pich uses localized traditional materials used in handicrafts, such as basket weaving, as structural frames. While his pieces explore Western minimalist approaches in aesthetics, ${ }^{41}$ Pich's ability to streamline memory and Cambodian identity begin with the "discovery" of rattan as a suitable medium for applying avant-garde formalist concepts. The agricultural materiality of the bamboo is subtly seductive to the eye and imbues the works with romance of natural craft. As a result, Pich's particular approach to what constitutes transnational Asian art is unlike the other Cambodian artists appropriating photography, performance, painting and video medium. ${ }^{42,43}$ Cambodian Rattan suggests that craft does not dilute intellectuality in contemporary art but creates a paradoxical image that is closer to the truth than the Khmer Rouge picture of permanent trauma.

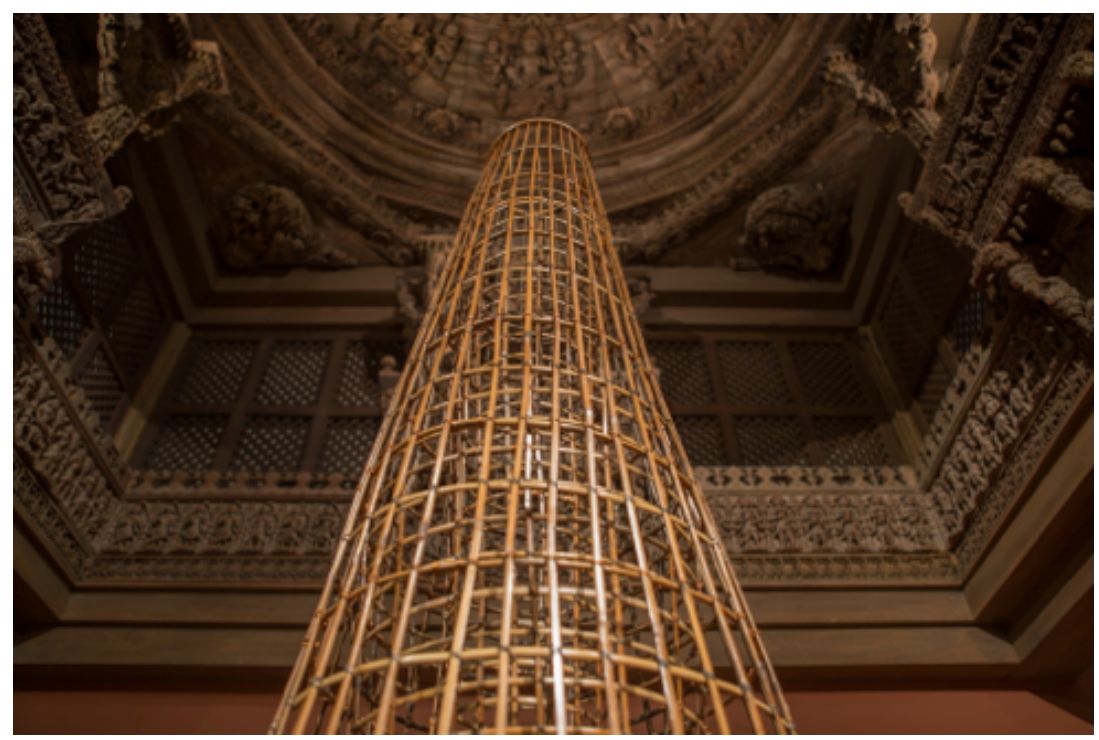

Figure 5. Sopheap Pich. Upstream (2005). Bamboo, rattan, metal wire and copper. 118 × 39 × 39 in. (299.7 x 99.1 x 99.1 cm). The Met. New York City. Image (C) The Metropolitan Museum of Art.

Pich's work also turns associations of inferiority into strength, trau- 
ma into art. The Met's interpretation of craft as a material-intensive process that guides the artist through a complex journey of consolidating identity is key to the Season of Cambodia's overarching aim. ${ }^{44}$ For example, the artist's process of craft making, ${ }^{45}$ especially the selection of bamboo from the hard and dangerous environments of rural Cambodian provinces, is on a video played on the screen in the gallery. ${ }^{46}$ These practices link Pich to Cambodia's largely agrarian society, to Western Arts and Crafts movements, to feminist contemporary artwork and the spirituality of Land Artists. ${ }^{47}$ Viewers imagine Pich twisting and weaving the strong yet flexible dried bamboo. They are thus encouraged to relate to Pich's sense of catharsis from trauma in technique. Rattan is designated a national material that helps Pich negotiate his identity between diaspora and Cambodian identity, ${ }^{48}$ finding Cambodian authenticity on the way. Furthermore, handicrafts form the bulk of goods that pass through tourist industries; the Season of Cambodia was also trying to promote this fact. ${ }^{49}$ In this merger of CLA's hopes for artists overcoming trauma and the Met's new definition of Cambodian authentic art, Pich's work becomes a platform to promote a new post-conflict understanding of the power of art. Pich's multilayered work addresses high art and craft, trauma and healing, destruction and post-conflict building. The CLA and the Met chose to emphasize art's transformative influence in aesthetics, psychology, and nationality. Through unconventional exhibition techniques, the Met furthered the nationalistic purposes of the Season of Cambodia. The Met presented the museum as a sacred site, where confronting tensions in art can help overcome post-conflict trauma while critiquing Western ideas of Cambodian art, culture and identity.

However, "authenticity" remains an embattled term within the Asian art community and the post-colonial discourse. The festival exhibition is framed by certain beliefs about how post-conflict reconstruction should come about and how criticisms of these beliefs should be considered. Caroline Hughes's studies of Cambodia prove to be especially enlightening about certain assumptions regarding trauma, capacity building, and flawed international intervention. ${ }^{50}$ In political terms, the exhibition and Season of Cambodia act as examples of international roles in the politics of authenticity in post-conflict reconstruction. By placing Sopheap Pich, a member of the Cambodian diaspora and returnee to the 
urban Phnom Penh, as the model for Cambodian nationality, Cambodian Rattan runs the risk skewing the potential for such agents to transform post-conflict politics in the right direction. According to Hughes, it is problematic as they "represent attempts to smuggle Western hierarchies of knowledge into post-conflict reconstruction efforts under the cover of ethnic solidarity, to the detriment of local participation and empowerment." ${ }^{51}$ Pich is, however, willing to admit these tensions. In response to a question regarding his status as an international representative of Cambodian art, he says "I'm still viewed as an outsider sometimes and other times not." ${ }^{52}$ Such tensions regarding authenticity on political and social levels seemed to be skimmed over in Cambodian Rattan..$^{53}$ Instead, the exhibition warrants the healing qualities of craft as a sign of authenticity in Cambodian art, furthering the nationalistic beliefs of Season of Cambodia.

\section{Conclusion}

The tensions that Cambodian Rattan: The Sculptures of Sopheap Pich raises deconstruct and illuminate the complexity of art from Cambodia. On one hand, Cambodia's status as a developing "post-conflict" nation involves the different but often overlapping interests of multiple actors at political and cultural levels. For young Cambodians, artists, museum institutions, American viewers, and the international community, the partnership of Cambodia Living Arts and the Metropolitan Museum of Art produced a space for rethinking assumptions about Cambodia's artistic past and present. By legitimizing the psychological power of art, innovating exhibition methods and building cultural diplomacy, the institutions portrayed a congruent message about how far Cambodia has come since the end of Khmer Rouge rule. In that process, the Met used Pich's craftsmanship and Cambodian identity to project a new standard for ethical, innovative and culturally sensitive ways of displaying contemporary art. The show's ability to question the Western gaze in art history and museum culture with Pich's work melds well with the Season of Cambodia's overall mission. Indeed, the new definitions and strategies of seeing craft as high and authentic Cambodian contemporary art prompts new research breaking down hierarchies within art historical media. Cambodian Rattan sets itself as a post-conflict resolution model 
for the assessment and critique of post-conflict resolution studies. Caroline Hughes's studies of the effectiveness and authenticity politics of international intervention in the form of the diaspora community, returnees and NGOs might criticize the homogenizing individuality of Pich's retrospective. But the exhibition is only part of the festival's diverse approaches and events that show heterogeneous and holistic points of view for post-conflict Cambodia. Cambodian Rattan nonetheless largely succeeds in revealing existing tensions, opening the possibilities of newly defined meanings and encouraging the developing efforts of Cambodia's artists. Whether CLA and the Met's efforts will translate into tangible sociopolitical effects in Cambodia's post-conflict peace building drive is Art and Craft in American Art. Minneapolis: University of Minnesota Press. 